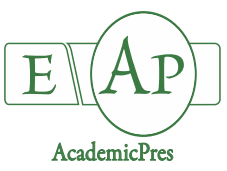

Lin J et al. (2021)

Notulae Botanicae Horti Agrobotanici Cluj-Napoca

Volume 49, Issue 1, Article number 12163

DOI: $10.15835 /$ nbha49112163

Research Article

\title{
Establish real-time monitoring models of cotton aphid quantity based on different leaf positions in cotton seedlings
}

\author{
Jiao LIN ${ }^{1}$, Jing-Cheng XU ${ }^{1}$, Lu-Lu MA ${ }^{1}$, Tian-Ying YAN ${ }^{2}$, \\ Cai-Xia YIN ${ }^{1}$, Xin $\mathrm{LV}^{1 *}$, Pan $\mathrm{GAO}^{2 *}$ \\ ${ }^{I}$ Shihezi University, College of Agriculture/ The Key Laboratory of Oasis Ecology Agricultural, Xinjiang Production and \\ ConstructionGroup, Shihezi832003,China; linjiao@stu.shzu.edu.cn; xjchhh@sina.com; malulu2018@sina.com; \\ yincaix@126.com; Lxshz@126.com (*correspondingauthor) \\ ${ }^{2}$ Shihezi University, College of Information Science and Technology, Xinjiang Production and Construction Group, Shihezi 832003, \\ China; yantianying@stu.shzu.edu.cn; gp_inf@shzu.edu.cn("corresponding author)
}

\begin{abstract}
Cotton aphids, Aphis gossypïglover, are major pest threats to cotton plants, leading to quality and yield loss of cotton. Rapid and accurate evaluation on the occurrence and quantity of cotton aphids can help precision management and treatment of cotton aphids. The occurrence rules of cotton aphids on different leaf positions in cotton seedling stage for two cultivars of cotton were studied. The quantity of cotton aphids in the whole cotton seedlings were predicted based on the single leaf cotton aphid quantity. The correlation analysis results showed that cotton aphids of single leaf were significantly and positively correlated with the infected time, the all leaves of the whole plant, the whole plant contained all leaves and branches. The variance analysis results showed that cotton aphids of single leaf were significant difference with the extension of infected time. Based on different leaf positions, monitoring models were constructed respectively. The modelling set's determination coefficient of 'Xinluzao-45' was greater than 0.8 , while 'Lumainyan-24' was greater than 0.6. The best monitoring leaf position was the third for 'Xinluzao-45', the sixth for 'Lumianyan-24'. From the data analysis, we can realize that it is feasible to construct a monitoring model based on the occurrence of cotton aphid in one leaf in cotton seedling, and different cotton varieties have different leaf positions. This will greatly reduce the investment of manpower and time.
\end{abstract}

Keywords: cotton aphid; cotton seedling; leaf stage; monitor model; quantity rules

\section{Introduction}

Aphis gossypii glover, a worldwide cotton pest, has different hazard levels and hazard areas at different leaf ages of cotton, resulting in lower height and leaf area of cotton plants, an increasing fall rate and lower yield. Now, manual field surveys are used to determine the occurrence and hazard level of aphids and to provide a basis for decision making in plant protection work. This method is accurate, but it is labour-intensive and timeconsuming to count whole-plant aphids. It is necessary to find an intermediate indicator to characterize wholeplant aphids, thus reducing the investment of labour and time. In addition, the spatial and temporal distribution of information on cotton aphids in cotton fields is not clear, resulting in the current production

Received: 19 Nov 2020. Received in revised form: 05 Feb 2021. Accepted: 10 Feb 2021. Published online: 22 Mar 2021.

From Volume 49, Issue 1, 2021, Notulae Botanicae Horti Agrobotanici Cluj-Napoca journal will use article numbers in place of the traditional method of continuous pagination through the volume. The journal will continue to appear quarterly, as before, with four annual numbers. 
of pesticide overspray, causing environmental pollution, which is not conducive to green and sustainable development of agriculture.

At present, the research on the quantity of cotton aphid mainly focuses on the relationship between the natural enemies of cotton aphid and its ebb and flow (Jiang et al., 2016; Yang et al., 2017), as well as the influence of environmental conditions (Wang et al., 2016; Yao et al., 2016) on the feeding of cotton aphid and its reproduction rate. Aphids damaged plants' organic and transmitted virous. So, it's important to reveal the occurrence regularity and damage characteristics of cotton aphid. A new method showed the mortality of $A$ phis gossypii was different among different layers after stratification (Jiang et al., 2019). With the development of information science and technology, the monitoring of crop pest quantity has changed from traditional manual statistics to image recognition counting with a good accuracy rate (Boissard et al., 2008; Jiao et al., 2018) However, the current researches based on image recognition counting are rarely carried out based on the distribution characteristics of pests on plants, but mostly based on sample size. Therefore, there is little basis for practical application. The selection of host plants by pests is related to the content of compounds in host plants and affects the number of pests (Huang et al., 2020).

Aphids are also the important insects of vegetables. The low tunnels reduced insect infestation and chewing herbivory leaf injury to brussels sprouts (Acharya et al., 2020). Aphids could product honey, which effected on the soil (Kyaw et al., 2020). Aphids, a type of sucking pest, reproduce rapidly and are usually caught and monitored in sticky traps. Experiments on drought and aphid infection of potato with different genotypes showed that drought sensitive genotypes had good tolerance to aphid (Quandahor et al., 2019). Image segmentation is one of the most important steps to count the number of pests. Different segmentation algorithms can be used to achieve the aim. Using threshold algorithms, Bodhe and Mukherji (2013) developed a system to detect and count whiteflies using image analysis. Using samples of yellow sticky traps from greenhouses, Qiao et al. (2008) proposed a model for density estimation of the silverleaf whitefly Bemisia tabaci based on image processing system which proved to be more efficient with medium and high densities of the pest. Using leaf samples, Maharlooei et al. (2017) designed a model for identification of soybean aphid (Aphis glycines) based on image processing techniques with different types of cameras and two illumination conditions and compared results with human counting. The best results were obtained with low illumination and Sony camera with $96 \%$ accuracy. Also using leaf samples, Chen et al. (2018) proposed a model for the segmentation and counting of aphid nymphs. This system showed a high accuracy when compared to human counting, but it is not selective and can be used for other pests. As a limitation, this and some of the systems described appear just to count and not distinguish between the whiteflies or aphid species. After the damage of cotton aphid, the hormone level of host plants will change, and the occurrence time of different host plants will be different (Koch et al., 2020). In production, insecticides are mainly used to protect cotton aphids. Studies have shown chemical control can make aphids rapidly produce resistance to insecticides (Ghazy et al., 2020). Therefore, it is necessary to accurately grasp the occurrence and development of aphids, so as to formulate effective control strategies. The spatial distribution of aphids on plants is not clear, but some studies have shown that the damage of aphids to host plant leaves is uneven ( $\mathrm{Li}$ et al., 2020). Under the threat of pests, the physiological and biochemical elements of the host plants will change, and the insect pests will interact (Eliezer et al.,2020; Gao et al., 2020). Low toxicity pesticides and appropriate hormone derivatives can inhibit and interrupt the growth cycle of pests (Jiang et al., 2020).

In this paper, for the first time, the relationship between the number of cotton aphid in different leaf positions and the number of cotton aphid in the whole plant was attempted to explore the best leaf position for monitoring the number of cotton aphid, so as to provide a theoretical basis for the monitoring of crop pests and the interdisciplinary research. Previous studies have shown that the traditional manual statistics of pest quantity requires a lot of energy and time, so most of the current pest research is based on the classification of pest damage. Quantitative change produces qualitative change. Timely and accurate control of the number of cotton aphids can better predict the occurrence of cotton aphids in the next few days, and provide decisionmaking basis for the control of cotton aphids in production. 


\section{Materials and Methods}

\section{Sample preparation}

Experiment was conducted in greenhouse of the Agronomy Experiment Station of Shihezi University, Shihezi City, Xinjiang Province, China, Latitude $44^{\circ} 18^{\prime} \mathrm{N}$ and Longitude $86^{\circ} 3^{\prime} \mathrm{E}$. The indoor ambient temperature was $15.5^{\circ} \mathrm{C}$ to $29^{\circ} \mathrm{C}$. The day and night were $16: 8$. The light intensity was $8000 \sim 10000$ lx. The test cotton varieties were 'Xinluzao- $45^{\prime}$ ' which stem was hairy and 'Lumianyan-24' which stem was less hairy, and the seeds were coated.

\section{Experimental design and treatments}

The cotton seeds were sowed on September 28th, 2019, with five seeds per pot. After the seedling emergence, two or three plants were kept per pot. The manual inoculation of cotton aphids was conducted when the fourth main stem leaf of the plant was fully expanded on November 20th, 2019, as Figure 1(A). Cotton aphids were feed on cotton in pots in August in the glass greenhouse with suitable environment and isolated by nylon mesh, meanwhile kept cottons alive always.

The data were collected from on November 25th, 2019 to December 30th, 2019, which was every five days. When collecting leaf aphid data, the leaves were collected from the bottom to the top in the order of leaf position, and the quantities of aphids on the leaves were recorded by manual. The quantities of aphids on the stem and petiole were recorded separately on the front and back sides. All data information was shown in Table 1. The leaf position diagram was shown in Figure 1(B). The manual inoculation of cotton aphid plants was shown in Figure 2(A) and uninoculated as Figure 2(B).

Table 1. Descriptive statistical analysis of quantity of single leaf during seedling stage

\begin{tabular}{|c|c|c|c|c|c|c|c|}
\hline \multirow{2}{*}{ Varity } & \multirow{2}{*}{ Plants } & \multirow{2}{*}{$\begin{array}{c}\text { Leaf } \\
\text { position }\end{array}$} & \multirow{2}{*}{ Samples } & \multicolumn{4}{|c|}{ Quantity } \\
\hline & & & & Maximum & Minimum & Average & Stdev \\
\hline \multirow{8}{*}{ 'Xinluzao-45' } & \multirow{8}{*}{12} & 1 & 12 & 132 & 0 & 46 & 43 \\
\hline & & 2 & 12 & 243 & 0 & 51 & 67 \\
\hline & & 3 & 12 & 460 & 5 & 132 & 172 \\
\hline & & 4 & 12 & 519 & 1 & 153 & 185 \\
\hline & & 5 & 10 & 570 & 0 & 177 & 202 \\
\hline & & 6 & 6 & 346 & 7 & 199 & 133 \\
\hline & & 7 & 3 & 310 & 24 & 205 & 128 \\
\hline & & 8 & 2 & 303 & 137 & 220 & 83 \\
\hline \multirow{9}{*}{ 'Lumianyan-24' } & \multirow{9}{*}{57} & 1 & 54 & 486 & 0 & 107 & 123 \\
\hline & & 2 & 56 & 367 & 0 & 123 & 118 \\
\hline & & 3 & 57 & 701 & 1 & 201 & 179 \\
\hline & & 4 & 57 & 911 & 0 & 244 & 223 \\
\hline & & 5 & 49 & 895 & 0 & 258 & 235 \\
\hline & & 6 & 32 & 939 & 40 & 325 & 271 \\
\hline & & 7 & 16 & 939 & 28 & 313 & 291 \\
\hline & & 8 & 7 & 1067 & 35 & 312 & 330 \\
\hline & & 9 & 5 & 276 & 23 & 146 & 85 \\
\hline
\end{tabular}

The basic data information contains all samples which are collected from on November 25th, 2019 to December 30th, 2019. Different varieties are listed separately. Under the same environment, the growth of individuals is also different. 


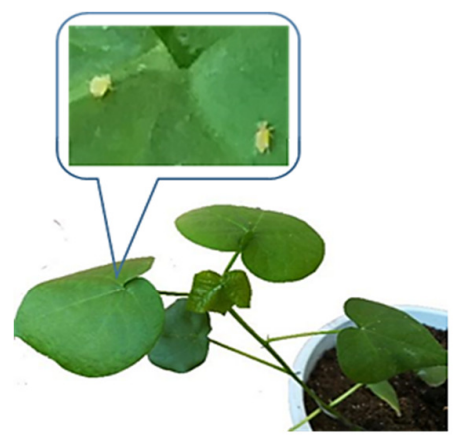

(A)

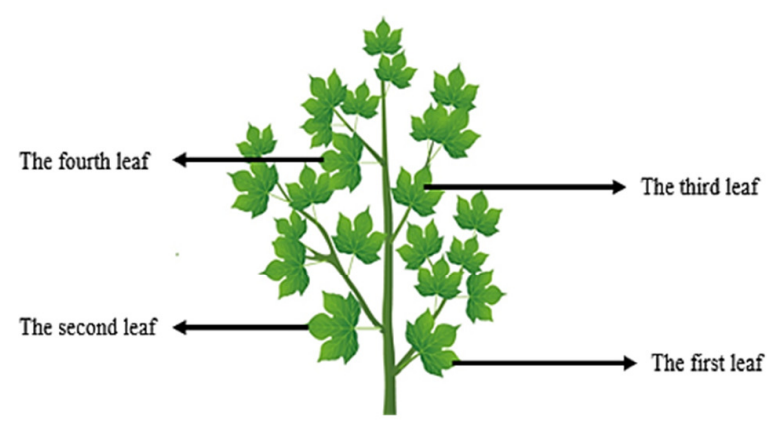

(B)

Figure 1. This figure shows respectively aphids inoculated and schematic diagram of leaf position (A)The manual inoculation of cotton aphids at fourth leaf stage. By soft brush, the manual inoculation of cotton aphids was conducted when the fourth main stem leaf of the plant was fully expanded. Each leaf was inoculated with four aphids which from the first leaf to the fourth leaf. Must be careful, the size and colour of aphids are the same; (B) Schematic diagram of leaf position delineation in cotton main stem. The main stem leaf is from the bottom to the top. This figure lists four main stem leaves, and the remaining leaves are classified and so on.

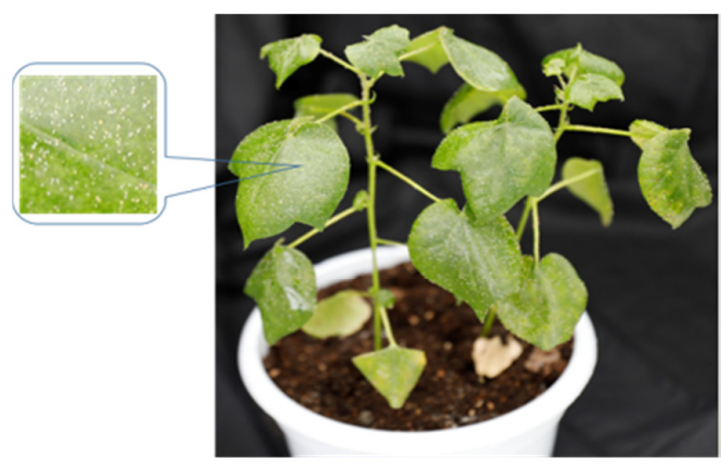

(A)

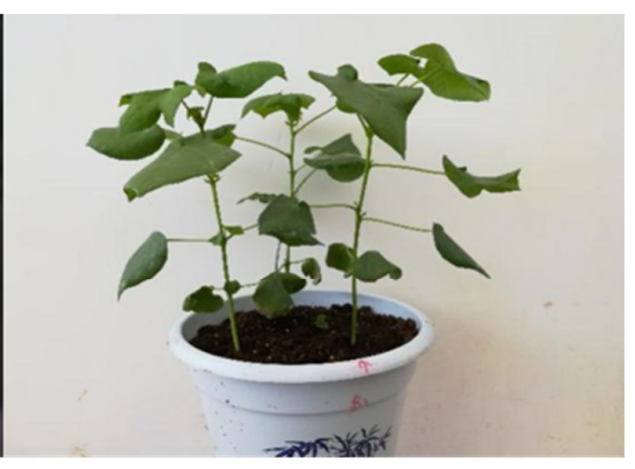

(B)

Figure 2. This figure shows respectively aphid infested plants and healthy plants at the same environment (A) The cotton plants covered with nylon mesh are infested by cotton aphid, and aphids distributed throughout the plant, aphids include winged aphids and wingless aphids; (B) The cotton plants covered with nylon mesh are healthy and keep away from inoculated plants.

\section{Statistical analysis}

The data processing was carried out in Microsoft Excel. Average, maximum, minimum, stdve were used to describe data characteristics. The statistical analysis was by IBM SPSS Statistics 24.0. Through the correlation analysis, we could get the correlation between the factors, and get the independent variables which have a greater impact on the dependent variables, which provided support for the model building.

\section{Results}

\section{Statistical analysis of cotton aphid quantity during cotton seedling}

Correlation of cotton aphids' quantities in cotton seedling of different varieties

We list five parameters for correlation analysis, which were infected time, leaf position, cotton aphid of single leaf, cotton aphid of all leaves and cotton aphid of plant. The correlation analysis results are shown in the Table 2. From the table, the correlation coefficient of different varieties is different but the trend is consistent. 
There is a significant positive correlation between the quantity of aphids and the infection time. It is mean that with the extension of infection time, the quantity of cotton aphids increased significantly. That regular can provide the basis for plant protection. Many studies on the quantity of cotton aphids are mainly regional, and there is little research on the distribution of aphids on plants. Experts' experience shows that aphids like to live in tender parts of plants. The correlation analysis of leaf position showed that there was a significant positive correlation between the quantity of single leaf aphid and leaf position, which was consistent with the previous research results. While single leaf was a significant positive correlation between all leaves and plant. The correlation coefficient was more than 0.8 for 'Xinluzao- 45 ', 0.79 for the 'Lumianyan-24'. The correlation coefficient of all leaves and plant it was more than 0.99 , which mean more aphids live on leaves. From that, we can know that the quantity of single leaf can be used indicated plant.

Table 2. Descriptive correlation analysis of five parameters during seedling stage

\begin{tabular}{|c|c|c|c|c|c|c|}
\hline & & \multicolumn{5}{|c|}{ Parameter } \\
\hline Varity & Parameter & $\begin{array}{l}\text { Infected } \\
\text { time }\end{array}$ & $\begin{array}{c}\text { Leaf } \\
\text { position }\end{array}$ & $\begin{array}{c}\text { Cotton } \\
\text { aphid of } \\
\text { single leaf }\end{array}$ & $\begin{array}{c}\text { Cotton } \\
\text { aphid of all } \\
\text { leaves }\end{array}$ & $\begin{array}{l}\text { Cotton } \\
\text { aphid of } \\
\text { plant }\end{array}$ \\
\hline \multirow{5}{*}{ 'Xinluzao-45' } & Infected time & 1 & & & & \\
\hline & Leaf position & $.285^{*}$ & 1 & & & \\
\hline & $\begin{array}{l}\text { Cotton aphid } \\
\text { of single leaf }\end{array}$ & $.786^{* *}$ & $.367^{* *}$ & 1 & & \\
\hline & $\begin{array}{c}\text { Cotton aphid } \\
\text { of all leaves }\end{array}$ & $.960^{* *}$ & $.266^{*}$ & $.808^{* *}$ & 1 & \\
\hline & $\begin{array}{c}\text { Cotton aphid } \\
\text { of plant }\end{array}$ & $.972^{* *}$ & $.272^{*}$ & $.811^{* *}$ & $.994^{* *}$ & 1 \\
\hline \multirow{5}{*}{ 'Lumianyan-24' } & Infected time & 1 & & & & \\
\hline & Leaf position & $.241^{* *}$ & 1 & & & \\
\hline & $\begin{array}{l}\text { Cotton aphid } \\
\text { of single leaf }\end{array}$ & $.720^{* *}$ & $.303^{* *}$ & 1 & & \\
\hline & $\begin{array}{c}\text { Cotton aphid } \\
\text { of all leaves }\end{array}$ & $.776^{* *}$ & $.265^{* *}$ & $.817^{* *}$ & 1 & \\
\hline & $\begin{array}{c}\text { Cotton aphid } \\
\text { of plant }\end{array}$ & $.742^{* *}$ & $.272^{* *}$ & $.799^{* *}$ & $.992^{* *}$ & 1 \\
\hline
\end{tabular}

*Notes: Cotton aphid of all leaves mean counting all of single leaf at the same plant. Aphids live on leaves and stem, so cotton of aphid plan means counting all leaves and stem. All samples where be used for correlation analysis which were collected from on November 25th, 2019 to December 30th, 2019, like table 1. Different varieties are listed separately. ${ }^{*}$ Notes: Different letters between cultivars denote significant differences (Duncan test, $\mathrm{p}<0.05$ ).

*Notes: Different letters between cultivars denote significant differences (Duncan test, $\mathrm{p}<0.01$ ).

\begin{abstract}
Analysis of variance for different leaf positions of cotton aphid quantity in cotton seedling of different cotton varieties

From Table 1, we can know that the 'Lumianyan-24' were growing well with nine main stem leaves, while the 'Xinluzao-45' were eight main stem leaves. Considering the effective analysis of the data, we choose five and seven leaves respectively. The follow figure shows the trends of different leaf position. From the follow figure, we can know that cotton aphids of single leaf are increasing with the infected time prolonging. In general, the quantity of cotton aphid of single leaf, 'Lumainyan-24' was greater than 'Xinluzao-45'. Figure 3 (A) showed that cotton aphid quantities of infected forty days were significantly greater than before in the same leaf position but the second leaf position. At the same infected time, there was no significant difference in different leaf positions but the second leaf position; Figure 3 (B) showed that leaf position of three, four and five were increasing always along the infected time, the other leaves were first increasing, then decreasing, and the increasing. At the same infected time, there was a significant difference in different leaf positions. So, we can see that different cotton varieties have different characters of changing trend about cotton aphid of single leaf.
\end{abstract}


From the Figure 3, we know that aphids on single leaf of 'Xinluzao-45' are less than Lumianyan-24. It maybe the stem's hairy. 'Xinluzao- 45 ' has fully hairy than 'Lumianyan-24'. Some study showed hairy can avoid? insects to move. With the infected time prolonging, aphids are not increase always like the leaf stage 2 of (a) and 1,2,7 of (b). Maybe it's changes of leaves' contents. That need further study to verify whether is it so.

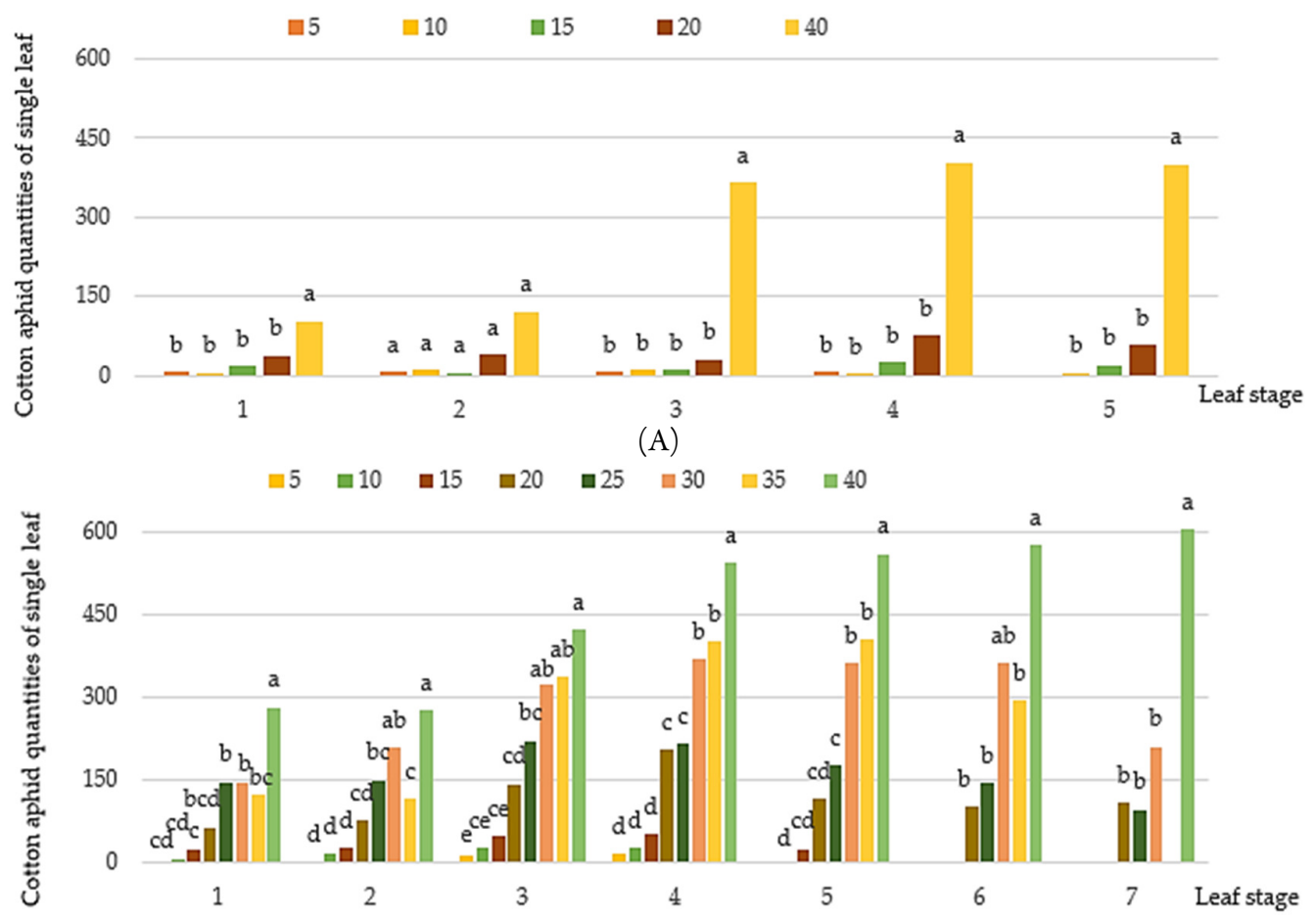

(B)

Figure 3. This is a figure which shows analysis of variance on different leaf stage

(A) The analysis of variance of 'Xinlizao-45'; (B) The analysis of variance of 'Lumianyan-24'. The legend of " $5,10,15,20,25,30,35,40$ " represent infection time respectively. The " 5 " means five days, and the remaining numbers are classified and so on. The (A) lack of three times' data of" $25,30,35$ ". In the figure, the significant difference was indicated by a, b, c, d according to the results.

*Notes: Duncan's multiple range test, different letters in the same leaf position indicated significant differences. $\mathrm{p}<0.05)$

According to the previous analysis, linear models were established to estimate the total cotton aphids based on different leaf positions respectively. The quantity of single leaf was used as independent variable, the quantity of plant was the dependent variable. $\mathrm{R}^{2}$ (correlation coefficient) and RMSE (root mean square error) are two indicators for evaluation model. As the follow table. For the 'Xinluzao- 45 ', the monitor model based the second leaf position was not suitable, while the other monitor models were significant with correlation coefficient greater than 0.81 . Considering correlation coefficient and RMSE, the best monitor model was based the third leaf position, with correlation coefficient was 0.85 , extremely significant, RMSE was 215.908 . For the Lumainya-24, all of monitor models' correlation coefficient were extremely significant, which were greater than 0.62. The best monitor model was based the sixth leaf position, with correlation coefficient was 0.851 , extremely significant, RMSE was 469.618.

From Table 3, it shows that linear model can be used for monitoring aphid's quantity. But on the seedling stage, the monitor leaf position was different for varieties. Maybe, it correlated with variety's characters. 'Xinluzao-45' was full hairy on stem, while 'Lumianyan-24' was less hairy. Meanwhile, further study needs to expand samples. 
Lin J et al. (2021). Not Bot Horti Agrobo 49(1):12163

Table 3. Descriptive linear models based on different leaf position respectively

\begin{tabular}{|c|c|c|c|c|}
\hline Variety & Leaf position & Monitor model & Modeling set & Validation set \\
\hline \multirow{5}{*}{ 'Xinluzao-45' } & 1 & $Y=17.675 x+19.277$ & $\mathrm{n}=6, \mathrm{R}^{2}=0.814^{*}$ & $\begin{array}{c}\mathrm{n}=6, \mathrm{R}^{2}=0.9271, \\
\mathrm{RMSE}=331.5\end{array}$ \\
\hline & 2 & $Y=8.23 x+377.744$ & $\mathrm{n}=6, \mathrm{R}^{2}=0.507$ & $\begin{array}{c}\mathrm{n}=6, \mathrm{R}^{2}=0.8113, \\
\mathrm{RMSE}=558.1\end{array}$ \\
\hline & 3 & $Y=5.198 x+139.767$ & $\mathrm{n}=6, \mathrm{R}^{2}=0.853^{* *}$ & $\begin{array}{l}\mathrm{n}=6, \mathrm{R}^{2}=0.976 \\
\mathrm{RMSE}=215.908\end{array}$ \\
\hline & 4 & $Y=4.509 x+11.653$ & $\mathrm{n}=6, \mathrm{R}^{2}=0.965^{\circ}$ & $\begin{array}{l}\mathrm{n}=6, \mathrm{R}^{2}=986 \\
\mathrm{RMSE}=333.5\end{array}$ \\
\hline & 5 & $Y=3.835 x+239.287$ & $\mathrm{n}=5, \mathrm{R}^{2}=0.933^{\circ}$ & $\begin{array}{c}\mathrm{n}=5, \mathrm{R}^{2}=0.9454 \\
\mathrm{RMSE}=423.7\end{array}$ \\
\hline \multirow{7}{*}{ 'Lumianyan-24' } & 1 & $\begin{array}{c}Y=10.084 x+ \\
210.14\end{array}$ & $\mathrm{n}=29, \mathrm{R}^{2}=0.738^{*}$ & $\begin{array}{l}\mathrm{n}=25, \mathrm{R}^{2}=0.78 \\
\mathrm{RMSE}=1006.15\end{array}$ \\
\hline & 2 & $\begin{array}{c}\mathrm{Y}=11.442 \mathrm{x}+ \\
59.163\end{array}$ & $\mathrm{n}=30, \mathrm{R}^{2}=0.622^{* *}$ & $\begin{array}{c}\mathrm{n}=26, \mathrm{R}^{2}=0.8465 \\
\mathrm{RMSE}=679.671\end{array}$ \\
\hline & 3 & $Y=8.75 x-204.475$ & $\mathrm{n}=34, \mathrm{R}^{2}=0.856^{*}$ & $\begin{array}{c}\mathrm{n}=23, \mathrm{R}^{2}=0.9223, \\
\mathrm{RMSE}=680.953\end{array}$ \\
\hline & 4 & $\begin{array}{c}\mathrm{Y}=6.863 \mathrm{x}- \\
172.919\end{array}$ & $\mathrm{n}=34, \mathrm{R}^{2}=0.829^{* *}$ & $\begin{array}{c}\mathrm{n}=23, \mathrm{R}^{2}=0.9361, \\
\mathrm{RMSE}=525.638\end{array}$ \\
\hline & 5 & $Y=6.777 x-23.317$ & $\mathrm{n}=31, \mathrm{R}^{2}=0.865^{* *}$ & $\begin{array}{c}\mathrm{n}=18, \mathrm{R}^{2}=0.9053, \\
\mathrm{RMSE}=721.171\end{array}$ \\
\hline & 6 & $\begin{array}{c}Y=5.431 x+ \\
621.673\end{array}$ & $\mathrm{n}=22, \mathrm{R}^{2}=0.851^{* *}$ & $\begin{array}{l}\mathrm{n}=10, \mathrm{R}^{2}=0.969 \\
\mathrm{RMSE}=469.618\end{array}$ \\
\hline & 7 & $Y=5.5898 x+1347$ & $\mathrm{n}=11, \mathrm{R}^{2}=0.657^{* *}$ & $\begin{array}{c}\mathrm{n}=5, \mathrm{R}^{2}=0.9119 \\
\mathrm{RMSE}=1039.6\end{array}$ \\
\hline
\end{tabular}

Notes: All samples are collected from on November 25th, 2019 to December 30th, 2019. Different varieties are listed separately. Under the same environment, the growth of individuals is also different.

*Notes: Different letters between cultivars denote significant differences (Duncan test, $\mathrm{p}<0.05$ ).

*Notes: Different letters between cultivars denote significant differences (Duncan test, $\mathrm{p}<0.01$ ).

\section{Discussion}

Cotton aphid is the main pest in the cotton seedling stage. By sucking leaf sap, it curls the leaves, and the aphid nectar secreted by it adheres to the leaf surface and affects the plant's leaf photosynthesis and breeds bacteria easily. In addition, in the cotton seedling stage, cotton aphids are easy to live in the cotton growth point, affecting the growth and development of cotton, and very easy to cause cotton "multiple growth points", and reproduction rate is fast which a short period of time is very easy to large outbreak, causing serious damage, so it is an important pest control in cotton production. Therefore, fast and accurate access to cotton aphid quantity in cotton fields is a key point for aphid control. At present, the traditional survey also relies mainly on manual field visual inspection method, through the survey site within the cotton aphid reproduction rate, hundred aphid amounts to classify the cotton aphid occurrence level or hazard level. Its essence is defined by the cotton aphid quantity. Although the data obtained in this way is more accurate, conducive to the accurate judgment of the insect situation, statistics on the whole cotton aphid occurrence is not only not very timely and also requires a lot of labour input. Therefore, it is urgent to find out the occurrence and distribution of cotton aphid on cotton plants.

In this study, by studying the occurrence pattern of cotton aphids during the cotton seedling stage of two different cotton varieties, we obtained that the quantity of single leaf cotton aphids is highly correlated with cotton varieties, and the quantity of cotton aphids in the middle and upper leaves of cotton is higher than the lower leaves of cotton, which also indicates that the habit of cotton aphids is to take the young leaf position, 
which is consistent with the results of previous research. The results of this study showed that during the cotton seedling stage, single leaf aphids were highest in leaf position 6, which was higher than other leaf positions. With the popularization and application of hyperspectral remote sensing technology, a large area of pest monitoring has been realized (Reisig and Godfrey, 2006; Zhang et al., 2017). However, due to the mechanism of spectral response of plants, most studies based on this technique only focus on the canopy and single leaf of plants, and little is known about the middle and lower part of plants and the overall pest situation. The purpose of this study is to study the distribution of cotton aphid on cotton plant and detect the optimal leaf position, which can provide ideas for the application of remote sensing technology in crop pest research. The results of this study showed that built monitoring models' single leaf was feasible. For future, we can study the different canopy's number of characteristics in? with other subjects, which will improve monitoring pest and decrees the cost and loss.

\section{Conclusions}

In this experiment, cotton aphids were inoculated artificially to damage cotton seedling plants. The quantities of cotton aphid in single leaf and plant were counted by manual. A total of 404 samples were collected. Through correlation and variance analysis, the best monitoring leaf position was determined respectively on cotton seedling stage. Through the implementation of model verification, the best monitor model for 'Xinluzao-45' was the third leaf position, while 'Lumianyan-24' was the fifth leaf position. Both of the two monitor models' correlation coefficient is greater than 0.85 . It is convenient to count cotton aphids manually and reduce the input of manpower and time. In this paper, the best monitoring leaf position is determined. In the future, the aphid identification and counting will be combined with image recognition technology, which will liberate manpower investment and make cotton pest management more efficient. But this study just on cotton seedling stage, not consider the flowering and boll stage which are most important for pest management. In the future, it will be going on to further study on the system.

\section{Authors' Contributions}

Conceptualization, J.L and X.L.; data curation, C.X.Y and J.C.X.; formal analysis, J.L and L.L.M.; methodology, T.Y.Y.; supervision, P.G.; writing-original draft, J.L.; writing-review and editing, X.L and P.G. All authors read and approved the final manuscript.

\section{Acknowledgements}

This work was supported by the Major Scientific and Technical Projects of Xinjiang Production and Construction Corps (grant number 2018AA004); The state shall guide local scientific and technological development projects (grant number 2019BT0826); National Natural Science Foundation of China (grant number 61965014).

\section{Conflict of Interests}

The authors declare that there are no conflicts of interest related to this article. 
Lin J et al. (2021). Not Bot Horti Agrobo 49(1):12163

\section{References}

Acharya TP, Welbaum GE, Arancibia RA (2020). Low tunnels reduce insect populations, insecticide application, and chewing insect damage on brussels sprouts. Journal of Economic Entomology 113:2553-2557. https://doi.org/10.1093/jee/toaa154

Bodhe TS, Mukherji P (2013). Selection of color space for image segmentation in pest detection. In: International Conference on Advances in Technology and Engineering (ICATE), Jan 23-25, 2013, Mumbai, India pp 1-7.

Boissard P, Martin V, Moisan S (2008). A cognitive vision approach to early pest detection in greenhouse crops. Computers and Electronics in Agriculture 62:81-93. https://doi.org/10.1016/j.compag.2007.11.009

Chen J, Fan YY, Wang T, Zhang C, Qiu ZJ, He Y (2018). Automatic segmentation and counting of aphid nymphs on leaves using convolutional neural networks. Agronomy 8:1-12. https://doi.org/10.3390/agronomy8080129

Gao XK, Xue H, Luo JY, Ji JC, Zhang LJ, Niu L, ... Cui JJ (2020). Molecular evidence that Lysiphlebia japonica regulates the development and physiological metabolism of aphis gossypii. International Journal of Molecular Sciences 21:1-16. https://doi.org/10.3390/ijms21134610

Ghazy NA, Okamura M, Sai K, Yamakawa S, Hamdi FA, Grbic V, Suzuki T (2020). A leaf-mimicking method for oral delivery of bioactive substances into sucking arthropod herbivores. Frontiers in Plant Science 11:1218. https://doi.org/10.3389/fpls.2020.01218

Huang XB, Wang YY, Zhang ZH (2020). Preferences and performance of Erythroneura sudra(Homoptera: Cicadellidae) on five fruit tree species (Rosaceae). Environmental Entomology 49:931-937. https://doi.org/10.1093/ee/nvaa057

Jiang BB, Guo BB, Cui JL, Dong YW, Cui L, Zhang L, ... Yang XL (2020). New lead discovery of insect growth regulators based on the scaffold hopping strategy. Bioorganic \& Medicinal Chemistry Letters. https://doi.org/10.1016/j.bmcl.2020.127500

Jiang H, Wu HX, Chen JJ, Tian YQ, Zhang ZX, Xu HH (2019). Sulfoxaflor applied via drip irrigation effectively controls cotton aphid (Aphis gossypii Glover). Insects 10:345. https://doi.org/10.3390/insects10100345

Jiang SL, Liu TJ, Yu FL, Li T, Parajulee MN, Zhang LM, Chen FJ (2017). Feeding behavioral response of cotton aphid, Aphis gossypii, to elevated $\mathrm{CO}_{2}$ EPG test with leaf microstructure and leaf chemistry. Entomologia Experimentalis et Applicata 160:1-10. https://doi.org/10.1111/eea.12475

Jiao LZ, Chen MX, Wang XT, Du XF, Dong DM (2018). Monitoring the number and size of pests based on modulated infrared beam sensing technology. Precision Agriculture 19:1100-1112. https://doi.org/10.1007/s11119-018-9576-3

Khaling E, Agyei T, Jokinen S, Holopainen JK, Blande JD (2020). The phytotoxic air-pollutant O3 enhances the emission of herbivore induced volatile organic compounds (VOCs) and affects the susceptibility of black mustard plants to pest attack. Environmental Pollution 265:1-12. https://doi.org/10.1016/j.envpol.2020.115030

Koch KG, Palmer NA, Donze-Reiner T, Scully ED, Seravalli J, Amundsen K, ... Sarath G (2020). Aphid-responsive defense networks in hybrid switchgrass. Frontiers in Plant Science 11:1145. https://doi.org/10.3389/fpls.2020.01145

Li XY, Huang HG, Shabanov NV, Chen L, Yan K, Shi J (2020). Extending the stochastic radiative transfer theory to simulate BRF over forests with heterogeneous distribution of damaged foliage inside of tree crowns. Remote Sensing of Environment 250:1-17. https://doi.org/10.1016/j.rse.2020.112040

Maharlooei M, Sivarajan S, Bajwa SG, Harmon JP, Nowatzki J (2017). Detection of soybean aphids in a greenhouse using an image processing technique. Computers and Electronics in Agriculture 132:63-70. https://doi.org/10.1016/j.compag.2016.11.019

Qiao M, Lim J, Ji CW, Chung BK, Kim HY, Uhm KB, ... Chon TS (2008). Density estimation of Bemisia tabaci (Hemiptera: Aleyrodidae) in a greenhouse using sticky traps in conjunction with an image processing system. Journal of Asia-Pacific Entomology 11:25-29. https://doi.org/10.1016/jaspen.2008.03.002

Quandahor P, Lin CY, Gou YP, Coulter JA, Liu CZ (2019). Leaf morphological and biochemical responses of three potato (Solanum tuberosum L.) cultivars to drought stress and aphid (Myzus persicae Sulzer) infestation. Insects 10:1-17. https://doi.org/10.3390/insects10120435

Reisig D, Godfrey L (2006). Remote sensing for detection of cotton aphid (Homoptera:Aphididae) and spider mite(Acari:Tetranychidae) infested cotton in the San Joaquin Valley. Environmental Entomology 35:1635-1646. 
Tun KM, McCormick AC, Jones T, Garbuz S, Minor M (2020). Honeydew deposition by the giant willow aphid (Tuberolachnus salignus) affects soil biota and soil biochemical properties. Insects 11:1-19. https://doi.org/10.3390/insects11080460

Wang L, Zhang S, Luo JY, Wang CY, Lv LM, Zhu XZ, ... Cui JJ (2016). Identification of Aphis gossypii glover (Hemiptera: Aphididae) biotypes from different host plants in north China. PLoS ONE 11:1-15. https://doi.org/10.1371/journal.pone.0146345

Yang F, Wu YK, Xu L, Wang Q, Yao ZW, Vladimir Z, ... Guo YY (2017). Species composition and richness of aphid parasitoid wasps in cotton fields in northern China. Scientific Reports 7:9799. https://doi.org/10.1038/s41598-017-10345-7

Yao YS, Han P, Niu CY, Dong YC, Gao XW, Cui JJ, Desneux N (2016). Transgenic Bt cotton does not disrupt the topdown Forces regulating the cotton aphid in central China. PLoS ONE 11:1-13. https://doi.org/10.1371/journal.pone.0166771

Zhang GL, Tao X, Zhang Z, Du YX, Lv X (2017). Monitoring of Aphis gossypii using green seeker and SPAD meter. Indian Society of Remote Sensing 45:361-367. https://doi.org/10.1007/s12524-016-0585-2
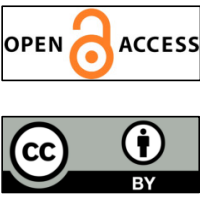

The journal offers free, immediate, and unrestricted access to peer-reviewed research and scholarly work. Users are allowed to read, download, copy, distribute, print, search, or link to the full texts of the articles, or use them for any other lawful purpose, without asking prior permission from the publisher or the author.

License - Articles published in Notulae Botanicae Horti Agrobotanici Cluj-Napoca are Open-Access, distributed under the terms and conditions of the Creative Commons Attribution (CC BY 4.0) License.

(C) Articles by the authors; UASVM, Cluj-Napoca, Romania. The journal allows the author(s) to hold the copyright/to retain publishing rights without restriction. 